\title{
A rare presentation of hypothyroidism
}

\author{
S. ALALADE, K. WEERASINGHE \\ WREXHAM MAELOR HOSPITAL WALES
}
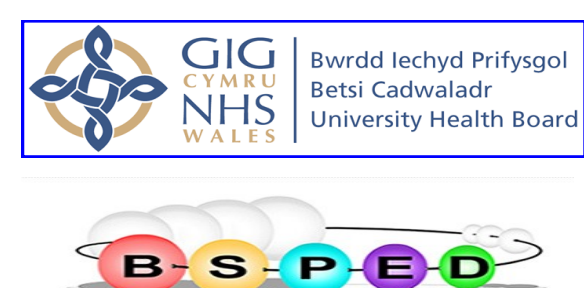

\section{Introduction}

Hypothyroidism is described as reduced serum concentrations of the thyroid hormone which can result from several causes which include thyroid hormone receptor resistance, autoimmune causes or disruptions along the hypothalalmopituitary axis. Psychiatric manifestations can include affective, psychotic and altered cognitive symptoms.

\section{Case Summary}

A 15 year old presented with history of low mood and paranoia of 2 months duration to her GP. She believed people were watching her, filming her and tracking her movements. She also reported a feeling of people hearing and seeing her thoughts. She refused to go school and withdrew from friends. She had excessive hair growth and irregular periods around the time of onset of her behavioural symptoms.

A diagnosis of polycystic ovaries was made following confirmation on pelvic ultrasound and blood tests (low sex hormone binding globulin of 19, FSH 5.4 and LH 27.9). She was started on oral contraceptive pills.

She was referred to psychiatrists and started cognitive behavioural therapy for about 6 months with no significant improvement. Following failure of behavioural therapy after 6 months, she was started on Quetapine25mg (antipsychotic). She had routine bloods done in accordance to guidelines for antipsychotic use in children. These included full blood count, urea and electrolytes, liver function tests, thyroid function tests, HbA1c and prolactin. Serum TSH was markedly high at 165 , serum free $\mathrm{T} 4$ was undetectable at $<1.9$ and normal thyroid peroxidise antibodies.

She was referred to the paediatricians following these results. There was no family of thyroid disease, celiac disease or diabetes. On examination, she did not have much eye contact .Her height was $152.5\left(2^{\text {nd }}-9^{\text {th }}\right.$ centile $)$ and weight was $72.1 \mathrm{~kg}\left(91 \mathrm{st}-98^{\text {th }}\right.$ centile). BMI $31.2\left(>99^{\text {th }}\right.$ centile). She had a small diffuse goitre without any palpable cervical nodes. She was commenced on thyroxine replacement therapy at 50micrograms which was gradually increased to 100 micrograms daily. Following thyroxine replacement therapy after two months she had improved energy levels and complete resolution of her paranoid delusions. She was weaned off her antipsychotics and discharged from psychiatric follow up.

\section{Table of results}

\begin{tabular}{|l|l|l|l|l|}
\hline & Thyroxine tx & 2weeks of tx & 4weeks of tx & 8 weeks of tx \\
\hline TSH $(0.35-5.5)$ & 165 & 105 & 59.7 & 16.2 \\
\hline T4 (7.0-17.0) & $<1.9$ & 2.8 & 8.7 & 11.4 \\
\hline T3 & & 3.2 & 3.6 & \\
\hline
\end{tabular}

\section{Conclusion}

Hypothyroidism could present with a wide variety of symptoms. It is however uncommon for the children to present with psychosis as the first presenting symptom. There are some case reports in literature for child psychosis due to do hypothyroidism. One report was by Smith $^{1} 1998$, he reported a 12 year old with altered behaviour who was found to have TSH $>100$ and T4 $<1$. He responded well to thyroxine therapy. Another report was by $\mathrm{Chung}^{2} 2010$ who reported an unusual case of myxoedema madness in a 12 year old. A report by Bhatara ${ }^{3} 1994$ presented a 13 year old with possible psychosis due to hypothyroidism whose symptoms improved with levothyroxine, however a 10 year follow up by Bhatara ${ }^{4}$ demonstrated that the child had a primary psychiatric disorder(OCD with depression) because he relapsed after discontinuation of SSRI and risperidone despite adequate doses of levothyroxine. Hypothyroidism was considered to be an aggravating factor. An article by Dali ${ }^{5}$ demonstrated cases of 3 females (aged 14, 16, 18.5 years) with psychosis associated with hypo and hyperthyroidism.

There is ample evidence that thyroid abnormalities need to be ruled out early in the initial management of psychiatric problems in children. This will enable early diagnosis and administration of appropriate therapy in these patients.

\section{REFERENCES}

Smith A L, Beattie R M Journal of royal society of Medicine 1998 Oct 91(10):537-538

Chung A Australian and New Zealand Journal of psychiatry 44(3)(pp292-294),2010

Bhatara et al Journal of Child and Psychopharmacology,vol (3)Win 1993 pp 199-212

Bhatara et al Journal of Child and Adolescent Psychopharmacology , vol 14(2), June 2004 pp315-323

Dali-Gottfried , International Journal of Adolescent Medicine and Health.vol 12(, 4)Oct- Dec 2004 pp 3223-329 